\title{
Concerns about the South African Mathematical Literacy curriculum arising from experience of materials development
}

\author{
Lynn Bowie and Vera Frith
}

\begin{abstract}
Marang Centre for Mathematics and Science Education, University of the Witwatersrand, and Numeracy Centre, Academic Development Programme, Centre for Higher Education Development, University of Cape Town
\end{abstract}

Lynn.Bowie@wits.ac.za and vfrith@maths.uct.ac.za

\begin{abstract}
In this paper we reflect on our experience of developing mathematical literacy material for the Further Education and Training (FET) band in South African schools, adult learners, university students and for participants in a youth development project. We use this experience to highlight some problems and concerns about the South African Mathematical Literacy curriculum for learners in the FET band and offer some cautions and suggestions. In particular we highlight the importance of the educational community in South Africa developing a shared understanding of what Mathematical Literacy is. We discuss the importance of distinguishing between Mathematics and Mathematical Literacy and of clarifying the role of Technology in Mathematical Literacy. We explore the difficulties and importance of a proper understanding of the contexts used to teach Mathematical Literacy and argue that more attention needs to be paid to the integration of Mathematical Literacy with other school subjects. Finally we raise some of the issues that a common final assessment task might have on the learning and teaching of Mathematical Literacy.
\end{abstract}

\section{Introduction}

We believe the introduction of Mathematical Literacy into South African schools presents both exciting opportunities and enormous challenges. Mathematical Literacy has the potential to provide learners, who previously did not continue with mathematics beyond grade 9, with access to the kind of skills that are crucial in order for them to participate meaningfully in the modern world. For this reason we believe it is important that the Mathematical Literacy that is taught in schools is of a high quality. We believe that it is vital that, as we implement the Mathematical Literacy curriculum and identify the difficulties we face, we engage with constructive criticism of the curriculum so as to improve it and make it more likely to achieve the goals for which it was introduced.

In this paper we reflect on our experience of developing mathematical literacy material for the FET band in South African schools, adult learners, university students and for participants in a youth development project. We use this experience to highlight some problems and concerns about the South African Mathematical Literacy curriculum for learners in the FET band and offer some cautions and suggestions.

One of the key issues that has emerged for us is that it is vital that the educational community in
South Africa develop a clear and shared understanding of what Mathematical Literacy is. This is a "slippery concept, the subject of lively debate" (Coben, 2003: 9) for at least the last decade particularly in Australia and England (where it is usually called 'numeracy') and in the United States (where it is most often called 'quantitative literacy'). This debate, which is comprehensively reviewed by Coben (2003), not only concerns itself with the definition of the concept, but also its relationship to mathematics itself. Hughes-Hallet (2001: 94) expresses this distinction as follows: "Mathematics focuses on climbing the ladder of abstraction while quantitative literacy clings to context. ... Mathematics is about general principles that can be applied in a range of contexts; quantitative literacy is about seeing every context through a quantitative lens."

This idea that Mathematical Literacy is mainly concerned with mathematics used in context is fundamental to all the definitions of mathematical literacy, whether it is seen as a social practice, form of literacy, a critical approach, or a behaviour (or even a set of skills). "At the very least then, the definitions garnered from this debate would agree that numeracy is to do with 'using maths in context' and that to be numerate is to have the "capacity to use maths effectively in context" 


\section{Concerns about the South African Mathematical Literacy curriculum arising from experience of materials development}

(Johnston, 2002: 4). Mathematical Literacy is not the same thing as basic mathematics, which provides learners with decontextualised mathematical skills. Some authors even claim that numeracy is "not less than or even part of mathematics, but something more than mathematics" (Johnston and Yasukawa, 2001: 280) being "the ability to situate, interpet, critique, use and perhaps even create mathematics in context..." (Johnston and Yasukawa, 2001: 279).

The debate about the meaning of the terms 'mathematical literacy' ('quantitative literacy' or 'numeracy') also brings to the fore the framing of the concept as an ability, behaviour or a social practice, rather than a 'subject' or area of study. The focus is on defining what a mathematically literate person does, rather than what collection of topics, skills and contexts mathematical literacy could be thought to consist of. So definitions contain statements like the following: "Numeracy: the ability to interpret, apply, and communicate mathematical information" (Adult Literacy and Lifeskills Survey Website) and "quantitative literacy is the ability to identify quantitative relationships in a range of contexts" (HughesHallett, 2001: 94). Evans (2000: 236) defines numeracy as social practice: "the ability to process, interpret and communicate numerical, quantitative, spatial, statistical, even mathematical, information, in ways that are appropriate for a variety of contexts, and that will enable a typical member of the culture to participate effectively in activities that they value" (cited in Coben, 2003:10).

The National Curriculum Statement offers the following definition, which frames Mathematical Literacy as a "subject" rather than a competency, a behaviour or a practice:

Mathematical Literacy is a subject driven

by life-related applications of mathematics. It enables learners to develop the ability and confidence to think numerically and spatially in order to interpret and critically analyse everyday situations and to solve problems. (Department of Education, 2003: 9)

This definition makes it clear that there are three key elements of Mathematical Literacy: the "content" (i.e. the mathematics), the "contexts" (i.e. the life-related applications, the everyday situations, the problems) and the abilities and behaviours that a mathematically literate person will exercise (confidence, thinking, interpreting, analysing and solving). However what is less clear is exactly how those three elements should play out together in the Mathematical Literacy classroom.

In the course of our work we have heard opinions from teachers, Department of Education officials, publishers, university lecturers and administrators about what they feel Mathematical Literacy will be. For some, Mathematical Literacy means teaching basic mathematics through "word sums". For others it means that the Mathematical Literacy learning programme a teacher develops must be structured around contextual themes from which the underlying mathematics can emerge. In some quarters it is portrayed as adequate for the educator simply to keep a mathematical eye on the media and create mathematical tasks based on what emerges from these observations. For others, it brings to mind strongly the mathematising notion of Realistic Mathematics Education. The central idea of Realistic Mathematics Education is "that mathematics can best be learnt from starting from a concrete, realistic situation that appeals to students" (Vos, 2002: 31). The problems in these realistic situations are mathematised by being "transferred to a more or less mathematical problem" (De Lange, 1996: 69) which can then be analysed with mathematical tools. In contrast, for others Mathematical Literacy is simply a remodelling of the old standard grade Mathematics curriculum.

The Subject Assessment Guidelines for Mathematical Literacy released by the Department of Education (September 2005) addresses the "content-context" debate head on:

On the one hand, mathematical content is needed to make sense of real-life contexts; on the other hand, contexts determine the content that is needed.

When teaching Mathematical Literacy, teachers should avoid teaching and assessing mathematical content in the absence of context. At the same time teachers must also concentrate on identifying in and extracting from the contexts the underlying mathematics or 'content'. That is avoid teaching and assessing contexts without being deliberate about the mathematical content. (Department of Education, 2005b: 7)

Although this begins to address some of the confusion, in our experience, the learning outcomes and assessment standards in the Mathematical Literacy curriculum do not provide a 
framework that gives clear guidance on how this content-context interplay can be achieved. In addition it is in places quite ambiguous about the specific content topics and contexts that should be taught. It is also quite vague about whether learners are expected to learn to use technology or not. In this paper we will discuss our observations and concerns about the curriculum under four headings, which highlight four issues in the current Mathematical Literacy curriculum that we believe need to be addressed.

\section{Issue 1: The Mathematical Literacy curriculum looks too much like Mathematics}

We have already mentioned that the international debate around mathematical literacy includes a strong thread that discusses the distinctions between mathematics and mathematical literacy (Hughes-Hallet, 2001; Coben, 2003). For example, in his paper "Mathematics and Numeracy: Two Literacies, One Language", Lynn Arthur Steen (2001) reviews a US government report on what the workplace requires of schools. He notes that this report organises mathematical ideas into entirely different categories to traditional mathematics. These range from basic skills (like arithmetic, estimation, understanding chance) to thinking skills (e.g. reasoning, planning) to more advanced competencies (e.g. allocating resources, technology, organising information, applying technology). He notes: "Algebra, geometry, trigonometry, and analysis sure sound different from resources, information, systems, and technology. These dramatically different perspectives on mathematics education - classical canon vs. modern employment - illustrate important differences between mathematics and numeracy. One conveys the power of abstraction, the other the power of practicality; one is organized by categories inherited from the past, the other focuses on the way knowledge is used in the information age; and one is encountered mostly in school, the other mostly in real life" (Steen, 2001: n.p.). The Mathematical Literacy curriculum does not attempt such a re-framing.

The Learning Outcomes for the Mathematical Literacy curriculum are:

Learning Outcome 1: Number and Operations in Context

Learning Outcome 2: Functional Relationships Learning Outcome 3: Space, Shape and Measurement
Learning Outcome 4: Data Handling.

The Learning Outcomes for the Mathematics FET curriculum are:

Learning Outcome 1: Number and Number

Relationships

Learning Outcome 2: Functions and Algebra

Learning Outcome 3: Space, Shape and

Measurement

Learning Outcome 4: Data Handling and

Probability.

Thus the Mathematical Literacy curriculum is divided into four outcomes using the same contentbased divisions as the Mathematics FET curriculum. This division frames the way educators will interpret the document. The intention of the curriculum authors was not that Mathematical Literacy learning programmes should be structured according to these divisions. In fact, in the Learning Programme Guidelines, they are at pains to point out that "Teachers should choose meaningful contexts to embed the content gleaned from the Assessment Standards in clusters across the Learning Outcomes where possible" (Department of Education, 2005a: 13) They also stress that "Teachers should view the learning outcomes as integrated and connected." In the Subject Assessment Guidelines they point out that in a Mathematical Literacy examination "Each question will integrate Assessment Standard from more than one Learning Outcome" (Department of Education, 2005b: 13).

However, the framing of the curriculum by the division into four learning outcomes is powerful. It is difficult for educators who have been educated under a traditional mathematics curriculum (and many of whom may have also taught a traditional mathematics curriculum) to break away from the idea of doing some number work, some algebra and graphs, some geometry and some statistics. It is particularly difficult to envisage a new way of structuring a learning programme in a Mathematical Literacy classroom when the curriculum itself constantly pulls one back to the traditional framing. Evidence of how difficult it is not to define the substance of a mathematical literacy class in purely mathematical terms can be seen in some of the curriculum support documents themselves.

For example, the Mathematical Literacy Subject Assessment Guidelines states that the grade 12 Mathematical Literacy examination will have a spread of questions that ensure that each of the learning outcomes is allocated $25 \%$ of the total marks. This allows the mathematical content to assume the importance of the major organising 


\section{Concerns about the South African Mathematical Literacy curriculum arising from experience of materials development}

principle for assessment. In addition, in the Learning Programme Guidelines (Department of Education, 2005a: 20) it is suggested that educators: "Consider what forms of assessment will be best suited to each of the Learning Outcomes and Assessment Standards and list these for the three grades", thus encouraging assessment practices that do not integrate assessment of the learning outcomes under the study of relevant contexts.

Another factor that made it difficult for us (and we believe will make it difficult for other educators) to view Mathematical Literacy, as defined by the Curriculum documents, as different from "an easier version of Mathematics" was some of the choices of mathematical content. For example, in grade 10 the curriculum states that, in terms of functional relationships we should include "linear, inverse proportion and compound growth in simple situations" and in grade 11 they expand this list to include "quadratic functions". These are all functions which have traditionally been part of South African school mathematics. It is difficult to escape the conclusion that this is the reason they have been included in the Mathematical Literacy curriculum. On the other hand, the inclusion of functions like piece-wise defined functions or step functions, which provide mathematical models for a number of real-life situations (e.g. parking fees, stepped tariffs for water use), would have been more in keeping with the intentions of the curriculum. Why are these then excluded from the list?

In asking these questions around the inclusion of content (particularly content that looks like traditional school mathematics) we are not necessarily arguing that content topics that are currently included should not be included, but we are arguing for a need to provide a clear "mathematical literacy" motivation for their inclusion. As Mathematical Literacy is a new subject, we believe this will help teachers, students, materials developers and the developers of the final assessment papers, to develop a better shared understanding of what Mathematical Literacy is. It will help us see the key goal behind the inclusion of any specific content, and so enable us to focus activities or problems we use in the classroom to achieve that goal. In addition recording the reasoning behind curriculum decisions also provides a resource for future development of the curriculum.

It seems clear that the Mathematical Literacy curriculum will have to be adapted and improved. It is being implemented for the first time in schools this year and the feedback from learners, teachers, parents, the business community, higher education and other interested groups should have an impact on how it plays out in practice. A motivation for why particular curriculum decisions were made allows us a framework to argue against or work with to further build the curriculum. This motivation will help to ensure that good ideas in the curriculum are retained, even if there are problems in the initial implementation.

We have pointed out that the assessment standards in the curriculum are largely specified in terms of mathematical content. There is a real danger that this can be interpreted to imply that Mathematical Literacy is slightly toned-down standard grade Mathematics "with word sums". This type of misconception is heightened by statements in the curriculum (Department of Education (DoE), National Curriculum Statement, Mathematical Literacy, 2003: 21, Assessment Standard 11.2.1) like "for example, interpret and critique quotations for two similar packages given by cell phone providers". This is essentially intended to be about simultaneous linear equations. Any real-life look at packages offered by cellphone providers is unlikely to end up in linear equations except perhaps through an extensive process of modelling using data about average patterns of usage and involving averaged tariffs. As most people would struggle to get access to this data one can only assume that the curriculum intends a "word sum" of the sort: "Cellphone package A costs R40 per month and R2 per minute of call time, cellphone package B costs R50 per month and R1,75 per minute of call time - compare." As this scenario bears no relation to reality, we would argue this kind of example is not Mathematical Literacy, but couching learning about linear equations in inauthentic supposedly real-life examples.

These kinds of "pseudo-contextualisations need to be avoided at all costs. Not only are they demeaning to adults and to youths, they fail to prepare them for participation in the varied discourses of the workplace" (FitzSimons, 2005: 38) This idea is also emphasised by Usiskin (2001: 84) who points out that artificial word problems "are not applications, nor should they substitute for them". If the Mathematical Literacy curriculum is to have credibility as a preparation for coping with the kinds of poorly-defined problems that make up the real demands of life and work, then inauthentic "applications" must be avoided. 


\section{Issue 2: Computer Technology}

"Current technology has caused much of the increase in the need for quantitative literacy. Without this technology, newspapers, financial institutions, scientific endeavors, and everything else that uses mathematics would not be the same" (Usiskin, 2001: 82). Thus, mathematical literacy increasingly requires the ability to make use of and to understand the role of computers in science, social science, professional and everyday life, and in the workplace. "The changing nature of workplaces and the ubiquity of computer-based systems for the automation and control of processes and the management of information, has brought about the need for employees at all levels to engage with these systems, to interpret their outputs and to make sense of the abstract models on which they are based" (Kent, Hoyles, Noss and Guile, 2004: 1). At its most fundamental level this knowledge includes the role and use of calculators and in the context of tertiary education and the workplace often includes the effective use of spreadsheets (Frith, Jaftha and Prince, 2005).

Hoyles, Wolf, Molyneux-Hodgson and Kent (2002) investigated the mathematical skills required in the workplace by studying aspects of work in the engineering, financial services, health care, food processing, packaging, pharmaceutical and tourism sectors in the United Kingdom. They report that their findings suggest that at all levels of the workforce "there is an inter-dependence of mathematical literacy and the use of IT in the workplace" and that "IT and mathematical skills are interdependent" (ibid:: 3). FitzSimons (2005: 29) reported on an extensive study of mathematical literacy practices in Australian workplaces and also concluded that aspects which are significant in mathematical literacy include "integrated mathematics and IT skills", and "an ability to create a formula (using a spreadsheet if necessary)". The importance of the use of appropriate technology is given recognition in the original Subject Statement (see for example National Curriculum Statement, Mathematical Literacy learning outcomes 10.2 .2 on p. $22 ; 10.4 .1$ on p. 30) and in the subject assessment guidelines (p. 7); although it is de-emphasised in the core curriculum which is to the assessed in the first three years of implementation of the new curriculum.

Clearly we are aware that there are some schools that lack electricity and many that lack adequate computing facilities or computer literate teachers. However, learning to use appropriate technology is a crucial aspect of mathematical literacy and we believe that the Department of Education needs to offer a clear plan of how and when this problem of inequitable access to knowledge about technology will be addressed. This needs to be incorporated into the way the Mathematical Literacy curriculum is written and seen as developing. A large proportion of learners are currently disadvantaged by lack of access to and knowledge of computer technology (and in many cases even scientific calculators). If this problem is not addressed these learners will invariably encounter barriers to progress and the "digital divide" between the richer and poorer members of society will be propagated.

There is a need for an investigation into the mathematical skills required in South African workplaces, similar to the ones referred to above, in England (Hoyles et al., 2002), Australia (FitzSimons, 2005) and the USA (Steen, 2001).

\section{Issue 3: Where does understanding the contexts fit in?}

Perhaps one of the key problems we came up against in developing mathematical literacy materials is that in order to mathematise a context one needs to have a good understanding of the context. This poses enormous challenges for teachers. Mathematical Literacy teachers will not only be required to understand mathematics, but also voting systems, mortgages, retirement funding, HIV/AIDS, global positioning systems, socially responsible trade (to name but a few of the contexts suggested in the current curriculum). Similarly, Mathematical Literacy learners will have to develop a good grasp of these contexts and herein lies a host of problems.

For example, the Mathematical Literacy curriculum has a focus on personal finances. The topics that learners are expected to deal with range from basic budgeting to compound interest to the effect of changing interest rates on mortgage repayments to comparing different retirement options. These are important skills and we feel that it is entirely appropriate to include them in the school curriculum. However, in planning the teaching of these topics we cannot assume that all learners in our country have an adequate experience of banks, let alone have an understanding of interest or of notions of risk and return on investments. If we expect the mathematical literacy learner to be able to use mathematics "to interpret and critically analyse everyday situations" (DoE, National Curriculum Statement, Mathematical Literacy, 2003: 9) then they have to have enough familiarity with the 


\section{Concerns about the South African Mathematical Literacy curriculum arising from experience of materials development}

situations or develop sufficient understanding of the situations in order to use their mathematical knowledge to analyse them.

When we attempted to create material to deal with the example suggested in the curriculum for grade 12: "calculate the net effect of different interest offerings and bank charges when saving schemes are considered" (DoE, National Curriculum Statement, Mathematical Literacy, 2003: 19, Assessment Standard 12.1.3), it became apparent that there were a large number of notions we should deal with if we really wanted learners to be able to do this in a way that would be useful for them. We felt that we should look at different kinds of bank accounts (transaction accounts, saving accounts), at features of these bank accounts (ATM cards, debit cards, cheques, stop orders, debit orders, etc.) and at practical issues (writing a cheque, using an ATM, reading a bank statement). All of this would require a large amount of teaching time to meet just one example listed under one assessment standard in the curriculum. Teachers, under time pressure in the classroom, and aware of the need to teach what will be examined are going to be faced with a dilemma.

We suggest that there are two ways to deal with this dilemma. The first is to "avoid teaching and assessing contexts without being deliberate about the mathematical content" (DoE, National Curriculum Statement, Subject Assessment Guidelines, 2005b: 7), and simply leave out the aspects of the context that are not mathematical. But this could leave us in a bizarre situation where we have a learner who can "calculate the effect of a fixed interest rate against probable variations in interest rates when buying a house or when choosing an investment" (DoE, National Curriculum Statement, Mathematical Literacy 2003: 19, Assessment Standard 12.1.3) but who does not know how to write a cheque or how to use an ATM safely!

The second is to take seriously the notion of integration. The curriculum stresses that integration is seen as important: "Integration is achieved within and across subjects and fields of learning. The integration of knowledge and skills across subjects and terrains of practice is crucial for achieving applied competence" (DoE, National Curriculum Statement, Mathematical Literacy, 2003: 3). But realistically, simply stressing that integration is important is not sufficient to ensure that integration will happen. Perhaps at some schools where there are exceptionally motivated teachers, the teachers will get together and find ways to create better learning opportunities for integration, but we believe that even they will struggle in the absence of curricula that pay more than lip service to it. We believe that the type of learning that can be achieved in mathematical literacy can be considerably strengthened through integration. However, we also believe that the place where serious attention needs to be paid to integration is at the curriculum level. If the design of curricula purposefully create spaces for integration then it will be more feasible for classroom teachers to act on this. For example, if in the Life Orientation and Mathematical Literacy curriculum understanding and managing personal finances was seen as a crucial skill to develop, then an extremely beneficial integrated learning experience could be developed. An integrated look at personal finances allows not only the time to investigate different bank accounts, charges and interest rates, but also to discuss attitudes to money, saving and risk, for example.

In a similar way an integrated approach could mean that learners look at data gathering and analysis within the context of HIV/AIDS or substance abuse in a way that gives the learners a fuller and more personally meaningful understanding of the context they are mathematising. In addition, topics like HIV/AIDS, substance abuse, teenage pregnancy and poverty are not necessarily going to be perceived as theoretical contexts to be mathematised by learners. For many learners these are very real issues they are struggling with in their daily lives and it could be uncomfortable and irresponsible to treat them as mathematical tasks only.

It is our belief that insufficient thought has been given to integration at the curriculum level and because of that we have missed an opportunity to provide a rich and meaningful learning experience for our learners. As a result of working on a project creating an integrated Mathematical Literacy, Life Orientation and Communication curriculum for National Youth Service Projects we conclude that, while integration is extremely difficult to achieve, the potential it has to enhance the learning of mathematical literacy, life skills and communication makes it worthwhile. In addition the integration ensures that mathematics, and the way the mathematics is taught, is truly aimed at enabling the learners to "interpret and critically analyse everyday situations" (DoE, National Curriculum Statement, Mathematical Literacy, 2003: 9) 


\section{Issue 4: A single national assessment requires that the curriculum is more specific about content and contexts}

At the end of grade 12 Mathematical Literacy learners will be assessed largely through a common final assessment task. All Mathematics teachers are familiar with the tension between providing quality mathematics education and covering the curriculum in a way that prepares learners for the final examination. This tension will no doubt play itself out in the Mathematical Literacy classrooms too. The implications of this for Mathematical Literacy as a school subject are too numerous and complex to do justice to in this paper. However, we do want to point out that our experience of developing material for FET Mathematical Literacy brought to light the fact that in many cases the curriculum does not specify precisely enough the content and, in some cases, the contextual knowledge, that learners will be assessed on.

For example, the grade 12 Assessment Standard 12.1.3 (DoE, 2003: 17) states that learners should "analyse and critically interpret a wide variety of financial situations mathematically, inclusive of .... critical engagement with debates about socially responsible trade." Socially responsible trade is the subject of vast debate, encompasses issues that range from environmental impact to global economic power relations. A critical engagement with the debates about socially responsible trade could (and does) form the basis of a year-long university level economics course. Alternatively socially responsible trade could be dealt with at a superficial level. The Mathematical Literacy curriculum provides no indication of where on this spectrum Mathematical Literacy teachers need to place the activities they develop for learners on this topic. Similarly in Learning Outcome 3, (DoE, 2003: 24) we are told that learners need to be able to work with the "perimeters and areas of polygons". Our experience in working with prospective Mathematical Literacy teachers has shown that some interpret this to mean taking another look at the perimeters and areas of the various quadrilaterals that were dealt with in grade 9 , whereas others feel this means they need to find a way to help learners deal with any polygon. In Assessment Standard 11.1.1 (DoE, National Curriculum Statement, Mathematical Literacy, 2003: 15) the curriculum says that learners need to be able to "find ways to explore and analyse situations that are numerically based, by... working with complex formulae by hand and with a scientific calculator, for example: $x=\frac{-b \pm \sqrt{b^{2}-4 a c}}{2 a} . "$ Does this mean learners must be able to find the roots of a quadratic equation or could we use another formula here?

In raising this issue and discussing these examples we are aware that we might sound irritatingly like the learner who continually asks "Will this be in the test?" instead of focusing on learning and understanding. However, unfortunately the common final assessment task will have enormous implications for learners and so making sure that learners are able to deal with what is in it will have to be taken seriously by any Mathematical Literacy teacher.

\section{Conclusion}

In this paper we have identified four issues that emerged for us in the process of developing mathematics literacy material:

- We need to develop a shared understanding of what the subject "Mathematical Literacy" is and how it differs from the subject "Mathematics";

- It is important that we address the issue of technology within the Mathematical Literacy curriculum;

- If we want to provide a responsible and meaningful learning experience then the contexts used within Mathematical Literacy need to addressed from both mathematical and non-mathematical points of view. As we rethink the curriculum we need to address the issue of the integration of Mathematical Literacy with other subjects more seriously;

- The fact that there will be a single national assessment for Mathematical Literacy at the end of grade 12 requires that the curriculum is clearer about what content and contexts learners need to be familiar with.

We offer these issues for consideration by the broader mathematics education community because we believe that the process of developing a high quality Mathematical Literacy curriculum requires that all people involved in the implementation of the curriculum should reflect on and share their experience. Through this process of sharing with and learning from each other we will not only strengthen what we are doing as we implement the current Mathematical Literacy curriculum, but we will also lay the basis for a strong revised Mathematical Literacy curriculum. 


\section{Concerns about the South African Mathematical Literacy curriculum arising from experience of materials development}

\section{References}

Adult Literacy and Lifeskills Survey website. Retrieved October, 2006, from http://nces.ed.gov/surveys/all/faq_all.asp?FAQ Type $=1$

Coben, D. (with Colwell, D., Macrae, S., Boaler, J., Brown, M., \& Rhodes, V.) (2003). Adult Numeracy: Review of Research and Related Literature. London: National Research and Development Centre for Adult Literacy and Numeracy. Retrieved February, 2006, from http://www.nrdc.org.uk/uploads/documents/doc 2802.pdf

De Lange, J. (1996). Chapter 2: Using and Applying Mathematics in Education. In A. Bishop (Ed.), International Handbook of Mathematics Education (pp. 49-97). Dordrecht: Kluwer.

Department of Education, South Africa. (2003). National Curriculum Statement Grades 10 - 12 (General). Mathematical Literacy. Retrieved February, 2006, from http://www.education.gov.za/content/document s/111.pdf

Department of Education, South Africa. (2005a). National Curriculum Statement Grades 10 - 12 (General). Learning Programme Guidelines Mathematical Literacy. Retrieved February, 2006, from http://www.education.gov.za/ content/documents/737.pdf

Department of Education, South Africa. (2005b). National Curriculum Statement Grades 10 - 12 (General). Subject Assessment Guidelines Mathematical Literacy. Retrieved February, 2006, from http://www.education.gov.za/ content/documents/754.pdf

Evans, J. (2000). Adults' Mathematical Thinking and Emotions: A study of numerate practices. London: Routledge/Falmer, Taylor \& Francis.

FitzSimons, G.E. (2005). Numeracy and Australian workplaces: Findings and implications. Australian Senior Mathematics Journal, 19(2), 27-40.

Frith, V., Jaftha, J.J., and Prince, R.N. (2005). Interactive Excel Tutorials in a Quantitative Literacy Course for Humanities Students. In: M.O. Thirunarayanan, and Aixa Pérez-Prado (Eds.), Integrating Technology in Higher Education (pp. 247-258). Maryland: University Press of America.

Hoyles, C., Wolf, A., Molyneux-Hodgson, S., and Kent, P. (2002). Mathematical Skills in the Workplace. Final Report to the Science,
Technology and Mathematics Council, Institute of Education, University of London. Retrieved February, 2006, from http://www.ioe.ac.uk/tlrp/technomaths/skills200 2/Maths-Skills-Workplace-Final-Report.pdf Hughes-Hallett, D. (2001). Achieving Numeracy: The Challenge of Implementation. In L.A. Steen (Ed.), Mathematics and Democracy, The Case for Quantitative Literacy (pp. 93-98). USA: The National Council on Education and the Disciplines. Retrieved February, 2006, from http://www.maa.org/Q1/093-98.pdf

Johnston, B. (2002). Numeracy in the Making: Twenty years of Australian adult numeracy. An investigation by the New SouthWales Centre, Adult Literacy and Numeracy Australian Research Consortium (No. 0868039446). Sydney: University of Technology, Sydney. Retrieved February, 2006, from http://www.staff.vu.edu.au/alnarc/publications/ 02Johnston.pdf

Johnston, B., and Yasukawa, K. (2001). Numeracy: Negotiating the World Through Mathematics. In B. Atweh, H. Forgasz, and B. Nebres (Eds.), Sociocultural Research in Mathematics Education. An International Perspective (pp. 57-73). New Jersey: Lawrence Erlbaum Associates.

Kent, P., Hoyles, C., Noss, R., \& Guile, D. (2004). Techno-mathematical Literacies in Workplace Activity. International Seminar on Learning and Technology at Work, Institute of Education, London, March 2004. Retrieved March 17, 2005, from www.ioe.ac.uk/tlrp/technomaths/Kent-LTWseminar-paper.pdf

Steen, L. (2001). Mathematics and Numeracy: Two Literacies, One Language. The Mathematics Educator, 6(1), 10-16. Retrieved October, 2006, from http://www.stolaf.edu/people/steen/Papers/twoli ts.html

Usiskin, Z. (2001). Quantitative Literacy for the Next Generation. In L.A. Steen (Ed.), Mathematics and Democracy, The Case for Quantitative Literacy (pp. 79-86). USA: The National Council on Education and the Disciplines. Retrieved February, 2006, from http://www.maa.org/q1/079-86.pdf

Vos, P. (2002). Like an ocean liner changing course: The grade 8 mathematics curriculum in the Netherlands, 1995-2000. Den Haag: CIP Gebegens Koninkelijke Bibliotheek. 